\title{
A homeopatia na rede pública do Estado de São Paulo: facilitadores e dificultadores
}

\author{
Homeopathy in the public network of the São Paulo State: \\ facilitating and hindering factors \\ La homeopatía en el sector público del Estado de São Paulo: \\ factores facilitadores y obstaculizadores
}

Wania Maria Papile Galhardi1*, Nelson Filice de Barros², Ana Cláudia Moraes Barros Leite-Mor ${ }^{3}$

Palavras-chave:
Saúde Pública
Homeopatia
Atenção à Saúde

Keywords:

Public Health

Homeopathy

Health Care

\section{Resumo}

Introdução: 0 desafio da integralidade na atenção à saúde, como configuração funcional e estrutural do cuidado, levou a Organização Mundial da Saúde a propor a incorporação das Medicinas Tradicionais e Medicinas Alternativas e Complementares para comporem a atenção à saúde, principalmente para os países em desenvolvimento. No Brasil, a oferta de práticas não ortodoxas nos serviços de atenção básica não é recente, mas em maio de 2006 foi publicada a Portaria nº 971 que propõe diretrizes para a incorporação das Práticas Integrativas e Complementares, sobretudo no nível primário. Este trabalho tem como objetivo analisar os fatores facilitadores e dificultadores da implementação da homeopatia no Sistema Único de Saúde dos municípios de São Paulo. Metodologia: Em 2008 foram identificados no DATASUS os municípios que ofereceram consultas homeopáticas de 2000-2007; estes dados foram analisados quantitativamente e, desencadearam questionamentos que foram utilizados para entrevistas com os gestores dos municípios, cujos resultados foram trabalhados quantiqualitativamente para a análise. Resultados: Dos 645 municípios de São Paulo, 47 ofertaram homeopatia e os gestores de 42 foram entrevistados. Estas últimas entrevistas indicaram que os fatores facilitadores estão relacionados à presença de médicos homeopatas no serviço; à adesão e disponibilidade do gestor em desenvolver a homeopatia; haver demanda de usuários perceptivos para a homeopatia; à ação dos Conselhos de Saúde; haver serviços de referência capazes de acolher a terapêutica homeopática e 0 baixo custo dos medicamentos homeopáticos. E, os dificultadores, com empecilhos como falta de estudos para a orientação dos gestores para a contratação de médicos homeopatas; a questões relacionadas à aquisição dos medicamentos; à priorização de outras especialidades médicas; ao desconhecimento da racionalidade médica homeopática; e preconceitos e dificuldades na implantação daquilo que é novo. Conclusão: os fatores facilitadores estão subsumidos às dificuldades apresentadas.

\section{Abstract}

Introduction: The challenge of health care integrity, concerning the functional and structural settlement of care itself, has caused the World Health Organization to propose the consolidation of Conventional Medicine with Alternative Medicine, in order to devise the health care intended for developing countries. Although the offer of non-conventional practice is not exactly recent in the Brazilian basic care, in May 2006, with the publishing of the Ordinance \#971, Brazil was given many guidelines referring to the addition of Complementary and Integrative Medicine into the primary level mostly. The purpose of this study was to analyze the factors that facilitate and hinder the

\footnotetext{
${ }^{1}$ Universidade Estadual de Campinas (UNICAMP). waniapg@terra.com.br

2 Universidade Estadual de Campinas (UNICAMP). nelfel@uol.com.br

${ }^{3}$ Universidade Estadual de Campinas (UNICAMP). mor.anaclaudia@gmail.com

${ }^{*}$ Autor correspondente.

Fonte de financiamento: nenhuma.

Conflito de interesses: Declararam não haver

Recebido em: 15/10/2011

Aprovado em: 26/03/2012
} 
implementation of homeopathy into the Single Health System in some municipalities in the State of Sao Paulo. Methodology: In 2008, the DATASUS index identified towns that had offered homeopathy appointments from 2000 to 2007 . These data were submitted to quantitative research that unleashed questions that composed the interviews with the city manager of each town. Data and results were analyzed through quantitative and qualitative research. Results: Out of the 645 municipalities in the State of Sao Paulo, 47 offered homeopathic assistance during that period, and the aiding factors for such offer were related to the presence of homeopaths in the health system; city managers with commitment and availability for developing homeopathy in their towns; the demand of users who are sensitive to the homeopathy proposal; the actions taken by Health Councils; the existence of referral services which support homeopathy therapy; and the low cost of homeopathic medicines. On the other hand, the hindering factors are related to obstacles in hiring homeopaths, as the lack of studies to guide the management; issues regarding the purchase of medicines; the priority given to other medical specialties; and the plain unfamiliarity with homeopathy, as well as the prejudice and difficulties of implementing anything new. Conclusion: The facilitating factors have been subsumed to the difficulties here presented.

\section{Palabras clave: \\ Salud Pública \\ Homeopatía \\ Cuidado de La Salud}

\section{Resumen}

Introducción: El desafío de la integridad en la atención de la salud, tales como el establecimiento funcional y estructural de la atención, llevó a la Organización Mundial de la Salud propuso la incorporación de la medicina tradicional y medicina complementaria y alternativa para componer cuidado de la salud, especialmente para los países en desarrollo . En Brasil, la oferta de prácticas poco ortodoxas en la atención primaria de salud no es nueva, pero en mayo de 2006 fue publicado en la Ordenanza nº 971 que propone directrices para la incorporación de las Prácticas Integradoras Complementares, especialmente en el nivel primario. Este estudio tiene como objetivo analizar los factores que facilitan o limitan la aplicación de la homeopatía en el Sistema Único de Salud de los municipios de São Paulo. Metodología: En el año 2008, em lo DATASUS fueron identificados los municipios que ofrecen consultas homeopáticas el período 2000-2007, y estos datos fueron analizados cuantitativa y preguntas fueron generado y se utilizaron para las entrevistas con los responsables de los municipios, cuyos resultados fueron cuantitativa y cualitativamente trabajado a su análisis. Resultados: De los 645 municipios de São Paulo, de 47 ofrece la homeopatía y los gerentes de los 42 fueron entrevistados. Qué indicó que los factores que facilitan son relacionada con la presencia de los médicos homeópatas en el servicio, el cumplimiento y la disponibilidad de los gerentes en desarrollo la homeopatía, hay demanda de los usuarios la percepción de la homeopatía, la acción del Consejo de Salud, podrá hacer referencia a servicios sede del tratamiento homeopático y el bajo costo de las medicinas homeopáticos.Y, lo que obstaculiza, son los obstáculos, como la falta de estúdios para orientar la gestión, en la contratación de médicos homeópatas, las cuestiones relacionadas con la adquisición de las medicinas, la priorización de otras especialidades médicas, la ignorancia en racionalidad homeopática, y los prejuicios y las dificultades en la aplicación de lo que es nuevo. Conclusión: los factores que facilitan se subsumen a las dificultades presentadas.

\section{Introdução}

A história da medicina mostra as influências da cultura, da economia, da epidemiologia e da política na construção do saber-fazer do cuidado em saúde. Da "arte de curar" observa-se a passagem pelo desenvolvimento anatomopatológico e pelo crescimento do uso da tecnologia, à perda do cuidado com a saúde. A medicina contemporânea prioriza a tecnificação dos atos diagnóstico e terapêutico, a superespecialização e o hospitalocentrismo ${ }^{1-3}$.

Em decorrência de tal cenário, desvalorizou-se o cuidado médico, desconsiderou-se a humanização; perdeu-se a concepção totalizante do homem como corpo, espírito, relaçôes afetivas e condiçóes de vida e trabalho ${ }^{3,4}$.

Em 1978, ocorreu a Conferência Mundial de Ministros da Saúde de Alma-Ata; ao final dos trabalhos concluiu-se pelas práticas integradoras e programas intersetoriais que intensificassem as açóes nos cuidados primários da saúde e auxiliassem a enfrentar o aumento progressivo do custeio da biomedicina. A Organização Mundial da Saúde (OMS) discutiu a necessidade de uma prática integral no cuidado à saúde; as nações economicamente mais desenvolvidas reorientaram seus sistemas nacionais de saúde e adotaram estratégias para seguir as orientaçôes e investiram na Medicina de Família e Comunitária 5 .

No mesmo sentido da atenção integral à saúde, a OMS propôs em 2002 que os Estados - membros incluíssem até 2005 a Medicina Tradicional e as Medicinas Alternativas e Complementares em seus serviços de saúde pública ${ }^{6}$.

Atendendo às recomendações da OMS, no Brasil, em maio de 2006, foi publicada a Política Nacional de Práticas Integrativas e Complementares (PNPIC), que refere a implementação dessas práticas no Sistema Único de Saúde (SUS), dentre elas a homeopatia. Na Política, o incentivo da oferta da homeopatia na atençáo primária é justificado pelo modelo da racionalidade homeopática que recoloca o sujeito no centro da atenção compreendendo-o nas suas dimensóes física, psicológica, social e cultural; fortalece a relação médico-paciente, contribuindo para a humanização da atenção; atua em diversas situações clínicas reduzindo a demanda por intervençóes; contribui para a melhora da qualidade de vida das pessoas e para o uso racional de medicamentos ${ }^{7-9}$.

Em pesquisa realizada sobre a atenção em homeopatia no Brasil, Salles ${ }^{10}$ identificou que 109 municípios e sete unidades da federação registraram consultas médicas homeopáticas 
de 2000 a 2005 no Sistema de Informaçóes Ambulatoriais do SUS, o que tornou evidente a pequena oferta da homeopatia aos usuários do Sistema Público de Saúde brasileiro.

Até agora, pouco se sabe sobre a atenção em homeopatia na rede pública dos municípios do Estado de São Paulo. Este Estado possui a maior população, o maior parque industrial e a maior produção econômica do Brasil, é reconhecido como fundamental para a vida socioeconômica e cultural do País, e ainda, estão nele concentrados os maiores núcleos formadores e produtores de tecnologia biomédica. No entanto, náo se encontram aí as experiências mais inovadoras e bem-sucedidas do SUS. Até 2009 não havia sido elaborada uma Política Estadual de Práticas Integrativas e Complementares e as experiências existentes nos municípios consistiam em práticas isoladas de profissionais ou de gestores da saúde ${ }^{11-13}$.

Diante disso, surgiu a intenção de conhecer os fatores que facilitam e os que dificultam o desenvolvimento da atençáo em homeopatia no SUS dos municípios do Estado de São Paulo.

Este artigo objetiva analisar os fatores facilitadores e dificultadores, para a implantação e implementação da homeopatia no SUS, dos municípios de São Paulo no período de 2000 a 2007.

\section{Método}

Utilizou-se da metodologia quantiqualitativa em duas fases. $\mathrm{Na} 1^{\text {a }}$ fase analisaram-se os dados quantitativos da produção ambulatorial de consultas em homeopatia registradas no Sistema de Informação Ambulatorial do SUS (www. datasus.com.br), a partir do ano 2000, visto que o código para consultas homeopáticas foi criado em 1999. Em planilha eletrônica, catalogaram-se os municípios de São Paulo com suas respectivas produçóes de consultas, ano a ano, durante o período de 2000-2007; então, analisaram-se a evoluçáo da oferta do atendimento.

A partir daí, surgiram questionamentos que foram utilizados como norteadores para uma $2^{a}$ fase da pesquisa, de cunho quantiqualitativo, realizada por meio de entrevistas com os gestores e/ou profissionais da saúde dos municípios.

As entrevistas foram realizadas por telefone, utilizando-se um instrumento semiestruturado constituído por questóes sobre: os fatores que facilitaram e dificultaram a atenção em homeopatia; a influência de outros níveis de governo na atenção; o conhecimento da PNPIC; legislação para homeopatia no município; a participação da população para a atenção; a contratação de médicos homeopatas; e a organização da atenção.
O método qualitativo na área da saúde permite a exploraçáo do campo onde uma prática está inserida, e a compreensão das forças culturais e sociais envolvidas na trajetória da implementação das práticas de saúde ${ }^{14,15}$. Desse modo, os depoimentos dos gestores, correspondentes às causas dos acontecimentos tornam o estudo explicativo quanto às diversas variáveis relacionadas à oferta ou não da homeopatia. Os dados das entrevistas foram tratados por análise de conteúdo a fim de identificar nos discursos, as atitudes, as escolhas e as resoluçōes dos sujeitos às demandas que se apresentaram ${ }^{16,17}$.

Diante do método utilizado nessa 2a fase, não seria possível a assinatura do Termo de Consentimento Livre e Esclarecido, o que foi compreendido pelo Comitê de Ética e Pesquisa da Faculdade de Ciências Médicas da Unicamp, que aprovou o projeto, segundo Protocolo de no 811/2008.

\section{Resultados e discussão}

\section{$1^{\text {a }}$ Fase}

Dos 645 municípios de São Paulo, 47 registraram atendimentos homeopáticos no SUS de 2000-2007 e têm o crescimento registrado na Figura 1.

Os municípios foram agrupados conforme o porte populacional ${ }^{18,19} \mathrm{e}$ foram considerados de pequeno porte os 17 municípios com até 100.000 habitantes; de médio porte os 24 municípios que possuem de 100.000 a 500.000 habitantes; e de grande porte 6 municípios com populaçáo acima de 500.000 habitantes.

Foram observadas interrupções e suspensões do atendimento, aumentos e decréscimos do número de consultas. E, do movimento da produção de consultas, criou-se uma tipologia que identifica os municípios como: Constantes - 25 municípios que tiveram atendimento contínuo, sem um movimento uniforme de ascensáo na produção de consultas; Descontínuos - 12 municípios que tiveram descontinuidade, que encerraram ou interromperam a atenção; e Tardios - 10 municípios que iniciaram a atenção a partir de 2001. Estes também foram classificados de acordo com o porte (Tabela 1) e foi analisado o crescimento da sua produção de consulta.

Nos Constantes, o crescimento do atendimento em homeopatia de 2000 a 2007 foi de $16,5 \%$, e a taxa de crescimento anual de 2000 a 2001 foi para decréscimo de $1,7 \%$; de 2001 a 2002 houve crescimento de $8,4 \%$; de 2002 a 2003 cresceu em 16,4\%; de 2003 a 2004 novamente decresceu em $0,5 \%$; de 2004 a 2005 houve crescimento de 
2\%; de 2005 a 2006, diminuiçáo de 6\%; e de 2006 a 2007, continuou diminuindo em mais $1,7 \%$, ou seja, desde 2005 vieram ocorrendo decréscimos no número de consultas homeopáticas. Nos Descontínuos, verificou-se um decréscimo da produçáo de consultas homeopáticas de 47\%. E, nos Tardios, houve crescimento de $98 \%$, por inclusão de municípios e não por crescimento do atendimento instalado, mas, de 2006 para 2007, a produção de consultas foi menor em 35\%.

Ao se tomar para análise todos os municípios, observa-se que, de 2000 a 2007 , houve crescimento médio de $14,6 \%$ na produção de consultas homeopáticas e, de 2006-2007, houve diminuição de $0,6 \%$, e em dois momentos específicos, 2003 e 2005, ocorreu a maior produção do atendimento.

Ao analisar a oferta de consultas homeopáticas por porte, identifica-se que os municípios de grande porte representam $12,7 \%$ dos estudados, os de médio porte $51,1 \%$ e de pequeno porte $36,2 \%$.

Os municípios que mais tiveram crescimento na atenção foram os de grande porte; a maioria está nos Constantes. Os municípios de médio porte, em maior número neste estudo, tiveram pequena contribuição para o aumento da produçáo de consultas. Os municípios de pequeno porte tiveram a maior diminuição da produção de consultas, quando comparados com os dos demais portes; e são maioria nos Tardios. O decréscimo no período de 2006-2007 foi relacionado aos grupos dos Constantes e Descontínuos, nos municípios de médio e pequeno porte (Tabela 2).

\section{$2^{\mathrm{a}}$ fase}

Dos 47 municípios que ofertaram atendimento homeopático, 42 responderam a entrevista.

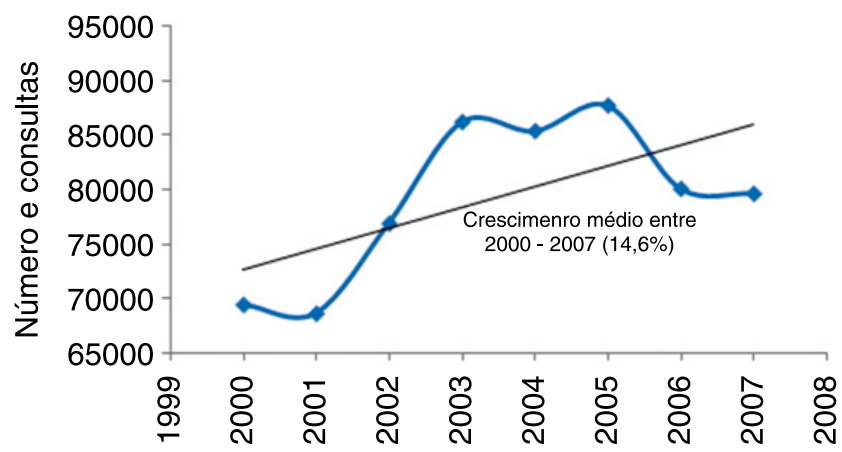

Figura 1. Produção de consultas nos municípios de São Paulo.

Tabela 1. Porte dos municípios por tipologia.

\begin{tabular}{lccc}
\hline Porte & Constantes & Descontínuos & Tardios \\
\hline Pequeno & 4 & 6 & 7 \\
Médio & 16 & 5 & 3 \\
Grande & 5 & 1 & 0 \\
\hline
\end{tabular}

Considerou-se no estudo como implementação a organizaçâo do atendimento homeopático; açôes que venham contribuir para a institucionalização da homeopatia na rede de serviços: adequação da área física, contratação e/ou alocação de médicos homeopatas, aquisição de medicamentos e criação de legislação municipal. Já por implantação, entenderam-se as ações pontuais relativas à homeopatia, sem incrementos para crescimento da atençáo.

A Figura 2 apresenta o número de municípios que implementaram a homeopatia por tipologia, significa: 47,6\% dos municípios pertencentes aos Constantes, $8 \%$ dos Descontínuos e 55,5\% dos Tardios implementaram a atenção em homeopatia.

Segue-se com os temas categorizados conforme o conteúdo expresso nas "falas" dos gestores, os quais representaram os fatores facilitadores e dificultadores para a atençáo em homeopatia.

\section{Facilitadores}

Os Constantes implementaram a homeopatia em 8 municípios de médio porte, 1 de pequeno porte e 1 de grande porte.

O elemento facilitador mais referido foi a presença de médicos homeopatas na rede, como se vê nas falas:

Tabela 2. Variação de crescimento segundo o porte do município.

\begin{tabular}{lc}
\hline \multicolumn{1}{c}{ Municípios } & Taxa de crescimento - 2000 a $2007(\%)$ \\
\hline Grande porte & 34,4 \\
Médio porte & 9,8 \\
Pequeno porte & -56 \\
\hline
\end{tabular}

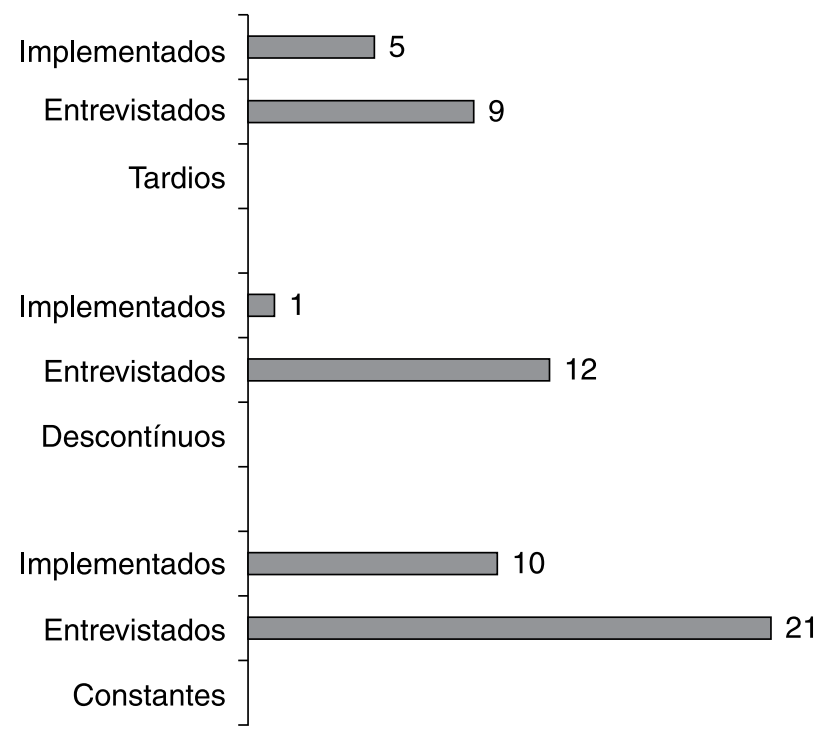

Figura 2. Municípios que implementaram a homeopatia. 
Em 1985 um médico homeopata do antigo INPS iniciou com práticas [...] em 1995 veio outra médica também homeopata [...].

Existe uma pediatra homeopata que tinha interesse em atender [...] então ela começou [...] e foi aumentando agora são três períodos.

O profissional mora no municipio e tem boa vontade, tudo iniciou por iniciativa própria dele [...] É uma pessoa iluminada! (Gestor).

Há 15 anos eu iniciei a homeopatia aqui [...] atendendo pediatria e só depois quando veio um pediatra homeopata [...] aumentamos o periodo de consulta [...] fazíamos no inicio reunióes com as pessoas [...] Era muito gostoso (médico).

Não foi evidenciada postura contrária do gestor para o atendimento homeopático realizado, pelo contrário, percebeu-se um tipo de permissão ou apoio. Para a implementação, ocorreu, na maioria das vezes, a destinação de mais um ou dois períodos do horário do contrato médico para a homeopatia. Portanto, os médicos que também são homeopatas continuam exercendo parte de sua carga horária na especialidade da biomedicina para a qual, inicialmente, foram contratados.

Outro elemento facilitador citado nos grupos dos Constantes foi haver demanda de usuários perceptivos para a homeopatia:

Existe aqui um clinico geral [...] atendendo alguns pacientes que tinham baixa resistência, doenças recorrentes e persistentes, $e$ assim está até agora. Ele sugere a homeopatia, se o paciente aceitar ele faz.

O único município do tipo dos Descontínuos que considerou ter implementado a homeopatia o fez antes de 2000, e é de médio porte. A implementação ocorreu com a criação do cargo de homeopatas e concurso público, o que possibilitou regularizar a situação dos médicos homeopatas que atendiam na rede contratados mediante vínculo com a especialidade alopática.

Novamente, como aspecto facilitador, é referido o fato de já haver um médico homeopata na rede, sendo que a descontinuidade da atenção em homeopatia ocorre quando este profissional se desvincula do serviço ou é locado em outro programa.

Teve um médico homeopata na rede pública, no ambulatório de especialidade que saiu do serviço [...] (encerrou em 2004).

Tivemos homeopatia em 2003, 2004 e 2005, porque tinha uma médica aqui que era homeopata e atendia doenças crônicas e de idosos, ela saiu do município. Tinha boa aceitação, depois abriu o PSF e os idosos foram absorvidos ai, não tivemos reclamaçóes (encerrou em 2006).

Outro fator facilitador foi a disposiçáo do gestor à homeopatia que, conhecendo a racionalidade, dedica-se à manutenção do serviço:
[...] quando vim para a Secretaria já existia um médico atendendo na rede básica, depois entrou outro e era homeopata e já começou a atender homeopatia. Dai abriu o cargo, foi feito concurso, os médicos homeopatas que já trabalhavam na rede prestaram e dois foram chamados [...] (não registrou atendimento em 2005).

Os Tardios tiveram maior percentual de municípios que implementaram a atenção em homeopatia. Dos 5 municípios do tipo Tardios que implementaram a atençáo, 3 são de pequeno porte e 2 de médio porte; fizeram-no de maneira consciente e organizada junto ao gestor. Não foi algo que aconteceu por acaso, como nas demais tipologias. Consideraram-se como principais fatores facilitadores nos Tardios a adesáo pelo gestor das propostas iniciais do médico homeopata e a açáo dos Conselhos de Saúde.

O Conselho de saúde organizou a atenção juntamente com a Secretaria e o médico, único homeopata, eu, [...] ambulatório uma vez por semana [...].

Vários médicos homeopatas estäo trabalhando na rede; a secretária da saúde está sensibilizada para a importância da homeopatia e a população está consciente do seu valor.

Era uma médica sanitarista que foi secretária de saúde e começou com a homeopatia. Foi aberto um concurso para médico homeopata, na verdade o concurso foi para clinico, mas o homeopata veio para prestar e agora faz as duas coisas, acupuntura e homeopatia.

O mesmo ocorreu no município de Juiz de Fora, em Minas Gerais, onde se mostrou a necessidade do envolvimento dos gestores locais, centrais, dos Conselhos de Saúde e/ou dos demais níveis de governo para a implantação e implementação da homeopatia ${ }^{20}$.

Também no grupo dos Tardios, foi citado, como elemento facilitador, o baixo custo dos medicamentos homeopáticos e a diminuição da busca pelas especialidades alopáticas. Tais consideraçôes mostram a coerência do gestor e seu conhecimento sobre o que a homeopatia pode proporcionar.

Não tivemos problemas com os medicamentos, pois são muito mais baratos [...], então o paciente compra. Se ele não puder comprar, vem até o serviço social, é avaliado e a Secretaria compra, não é dificil; é mais barato. E diminui muito o custo, diminui as idas ao especialista, diminui os exames e diminui a quantidade de medicamentos.

Aqui nós compramos os medicamentos quando a pessoa passa pela assistência social; são baratos, isto é ótimo, diminui o custo. Existem pessoas que precisariam de medicamentos mais caros e resolve com estes. Os municípios que implementaram a homeopatia, ainda apontaram os médicos homeopatas e os gestores que eram sanitaristas como facilitadores para a implementação. Apesar disso, mostrou-se também como fator 
facilitador o município ter serviços de referência capazes, para acolher a terapêutica homeopática, mesmo que esteja alocado no setor secundário da atenção.

Eu acompanho esta implantação a partir de 2005, aqui sempre foi um Centro de Reabilitação Neurológica e para se adequar ao atendimento passou [...] para uma equipe maior com [...] um homeopata e um médico acupunturista. Eles implantaram um projeto especifico para portadores de dores fantasma em amputados, a homeopata também atende outras patologias, aqui mesmo, são os outros profissionais daqui quem encaminham.

Iniciou com médicos na atenção em UBS, mas sobrecarregou, então resolvemos passar só para o ambulatório do Adolescente [...].

Têm-se então como fatores facilitadores para a implantação e implementação nos municípios estudados, principalmente: 1) a presença de médicos homeopatas no serviço; e 2) a adesão e disponibilidade do gestor em desenvolver a homeopatia. Mostram-se também como fatores determinantes na implementação: 3) haver demanda de usuários perceptivos para a homeopatia; 4) a ação dos Conselhos de Saúde; 5) haver serviços de referência capazes de acolher a terapêutica homeopática; e 6) o baixo custo dos medicamentos homeopáticos. Contudo, nenhum dos entrevistados fez referência à PNPIC como um incentivador ou facilitador para a atenção em homeopatia.

A implementação ocorreu principalmente em municípios de médio porte, embora não fossem eles os maiores produtores de consultas homeopáticas; ficando os de grande e os de pequeno porte apenas mantendo o atendimento iniciado, no entanto, foram aqueles de maior porte que produziram um maior número de consultas; indicativo de crescimento da demanda de usuários para homeopatia nestes municípios.

\section{Dificultadores}

A principal dificuldade citada pelos entrevistados dos municípios Constantes é a contrataçáo de médicos homeopatas. A contrataçáo foi dificultada por três fatores: não existiram profissionais interessados nos concursos; não se conseguiu justificar a contratação de profissionais homeopatas; e não haver meios de demonstrar a existência de demanda reprimida no serviço.

[...] foi criada vaga e aberta inscrição em concurso público, mas não houve interessado.

[...] ainda não temos concurso para homeopatas estamos pedindo para o Secretário.

Não existe demanda que me obrigue contratar para a homeopatia [...].

Os médicos não são contratados como homeopatas, são contratados como GO, Pediatra e médico, mesmo que sejam especialistas, não existe concurso para nenhum especialista. É então necessário o Plano de Cargos e Salários para adequar os médicos.

Outro grande problema é não ter produção científica para justificar que a homeopatia funciona para contratar médicos [...].

[...] os homeopatas neste momento estão aposentando e outro não há demanda que me force contratar, os homeopatas sentem a demanda, mas não são capazes de me dar números [...].

Também houve a influência de instância superior contrária à homeopatia, ou seja, numa cidade o obstáculo deveu-se ao Prefeito Municipal, porém, como a atençáo em homeopatia já era legitimada, os homeopatas e o gestor se mobilizaram. Amparados pela PNPIC, passaram da atenção básica, na qual o serviço era sentido como diluído e sem força, e se concentraram na atenção secundária, constituindo o Centro de Práticas Integrativas.

[...] uma vez um prefeito quis acabar com a homeopatia e a população reivindicou, então não acabou [...] a homeopatia era pulverizada pela rede, usamos a PNPIC [...] alugamos e montamos o Centro de Terapia Integrativa e Complementares [...].

Outros gestores relataram como fator dificultador terem que vencer todas as "prioridades" na saúde municipal, como o PSF e as especialidades, antes de atentarem para a homeopatia.

[...] a homeopatia não é prioridade. Eu me sinto uma traidora, fiz homeopatia e náo implantei [...].

[...] não temos perna para tudo, a gente quer, mas é dificil.

[...] as necessidades das demandas são outras.

A ideia é colocar uma unidade de referência para a homeopatia, pois só assim seria direito de todos, teríamos um serviço onde todos poderiam ter acesso e não só a população local. Estas (existe) duas médicas em unidade só dão atendimento para poucos, se os outros descobrem que só alguns têm este tratamento podemos ter problemas. E, muitas vezes não podemos abrir mão de uma pediatra, nossa prioridade é sempre suprir a atenção básica [...] ou teríamos que ter homeopatia em todas as unidades básicas, o que seria impossivel temos 11 aqui, então para dar vazão a tudo, o ideal é que fosse como outra especialidade [...]. Eu conheço o resultado da homeopatia, sei que é bom e acredito, acho que deve crescer, mas é um "pingo no oceano", penso que em todos os municípios são assim [...]: a dificuldade de encontrar médico para o PSF e ter que suprir esta necessidade e só depois que todas as unidades estiverem com seus médicos, direitinho funcionando é que se abre espaço para a terapia alternativa.

As dificuldades de aquisiçáo dos medicamentos, a falta de farmácia própria e de medicamentos na rede, também tiveram destaque como impedimento e foram apontadas algumas questões: os medicamentos são individualizados, 
os homeopatas seguem diferentes linhas, a maior diluição contribui para o aumento do custo dos medicamentos.

Falta de disponibilidade da medicação homeopática para a população assistida.

Para a farmácia existe um contrato mediante licitação, o paciente vai buscar o medicamento após a consulta e o município paga, a dificuldade é adequar os medicamentos com a entrada de outros médicos que têm outras linhas [...] para os medicamentos de maior dinamização, que custam mais caro.

[...] nosso sonho é ter farmácias que manipulem os medicamentos [...] o valor que hoje pagamos pelos medicamentos, pode ser usado na adequação da área física da farmácia e compra de equipamentos, e sairá mais barato.

Os medicamentos de homeopatia são difíceis, são individualizados, então não existe farmácia para manipular [...].

Outro dificultador é o tempo utilizado nas consultas homeopáticas versos a demanda de consultas. $\mathrm{O}$ médico, tal como nos demais serviços públicos, é pressionado quanto à produção de consultas. O gestor percebe a necessidade de resolver a "queixa" imediata do usuário e considera bons os documentos sobre promoção de saúde e prevenção de doenças, embora admita que na prática do serviço, deve-se priorizar $o$ atendimento da demanda.

(Existe) a precária divulgação do início das atividades (homeopatia), tanto para o público em geral quanto para a própria rede municipal de saúde [...].

[...] a dificuldade se relaciona com o tempo para a consulta, cobra-se produção, é difícil mudar a mentalidade do queixal conduta, todos os documentos estão bem escritos, muito lindo, perfeito no papel, a prevenção das doenças e promoção social, mas quando vamos para a prática, a demanda, tem que produzir [...].

$\mathbf{O}$ desconhecimento da racionalidade médica homeopática, somado às intençóes políticas partidárias, colabora para que a prioridade em saúde continue centrada na "queixa-conduta" e a ela direcionada, mantendo um modelo hospitalocêntrico, contrariando os princípios que regem o SUS, o que também foi tratado por outro autor em pesquisa sobre a homeopatia ${ }^{21}$.

Os usuários não têm aderência à homeopatia e não há demanda. As agendas vazias demonstram um serviço desnecessário, o que justifica, na percepção dos gestores, a não implementação ou a implantação de um novo serviço, cujo paradigma é desconhecido para a maioria das pessoas.

[...] não tem demanda que justifique implementar o serviço.

[...] não tem aderência da população, existe muita falta às consultas.

A principal dificuldade apontada pelos gestores dos municípios do tipo dos Descontínuos foi a aquisiçáo e fornecimento de medicamentos na rede. Os demais municípios se voltaram para as necessidades mais imediatas na gestáo, dentre elas o PSF, sendo que a homeopatia ficou em segundo plano.

A dificuldade na implementação é que era um médico só, $e$ ele teve que ir para a USF (alopatia). A população reivindica $P A$ (Pronto-Atendimento) 24 horas, tem que implantar PSF, tudo isto gera uma insatisfação na população, então temos que priorizar (encerrou em 2002).

Além destas questóes, houve "falas" que demonstraram dificuldades com relação à implantaçáo do novo.

Pretendo colocar as práticas integrativas na rede, mas hoje estou tendo que alinhar toda a Secretaria, apago fogo, estou cuidando das questöes muito básicas, até reformas de área física, adequando a rede básica, implantar o novo é difícil (encerrou em 2011).

Nos municípios Tardios, foi considerada a discriminação da homeopatia, enquanto racionalidade médica e, consequentemente, a dos médicos homeopatas, como fator dificultador. Tal fato demonstra o desconhecimento sobre a homeopatia e a disputa de poder com a biomedicina.

[...] bom, alguns não acreditam (na homeopatia), ainda hoje existe resistência por parte de alguns médicos.

A dificuldade, na verdade, só existia em outras gestóes, por não valorização do atendimento homeopático e todo tipo de discriminação à homeopatia.

[...] é preciso ter paciência com a homeopatia e as mães são imediatistas. Elas querem ver o resultado rápido, então (a atençáo) continua somente com aqueles que querem a homeopatia!.

A outra questão levantada na fala dos gestores é a dificuldade na contrataçáo dos homeopatas. Referem-se às dificuldades para fixar médicos em cidades de pequeno porte. Acredita-se que uma possibilidade é formar os médicos já lotados na atenção básica.

[...] pretendemos abrir concurso, acho que o recurso humano especializado é o mais difícil, porque a ideia é ampliar na atenção básica. Temos que formar os médicos [...].

Bom, o problema são os médicos, não cumprem horários, atendem 3-4 e não ficam no serviço, os problemas são complexos, mas seria muito bom se fosse implementado. Bom, agora está muito no começo (da gestáo) [...].

Durante toda a trajetória histórica da homeopatia, com períodos de ascensáo e queda, ela esteve presente no Sistema Público de Saúde Brasileiro. No entanto, mantém-se tradicionalmente em consultórios médicos privados, tornando-se disponível a certa parcela da população cujo nível socioeconômico privilegiado permite escolhas sobre o seu tratamento médico. Diferentemente das demais especialidades, a homeopatia não parece ser percebida como necessária nem pelos usuários do SUS e menos ainda pelos gestores. 
Já se percebe que os usuários do SUS ainda pouco experimentaram o tratamento homeopático e pouco se beneficiaram. Deste modo, obviamente, eles são incapazes para requerer algo que desconhecem como princípio, cultura e terapêutica. Isso leva a homeopatia a se distanciar da realidade do Sistema Público de Saúde e da legitimação social, imputando-se como elemento facilitador dessa atenção apenas a disponibilidade do médico homeopata para atender com homeopatia.

Os gestores também não encontram justificativas para a contratação de profissionais, uma vez que inexistem estudos que demonstrem cientificamente a efetividade da homeopatia, bem como avaliaçóes do custo e dos benefícios proporcionados para que investimentos possam ser destinados à implantação e implementação da homeopatia.

Verifica-se que, de maneira geral, nos relatos dos gestores, o pequeno atendimento homeopático não demonstra impacto nos serviços de saúde. Isso colabora para que as prioridades na saúde continuem excluindo a homeopatia como uma possibilidade terapêutica integrativa e complementar.

Têm-se então como fatores dificultadores para a implantação e implementação da homeopatia: 1) os empecilhos na contratação de médicos homeopatas; 2) as questóes relacionadas à aquisição dos medicamentos; 3) a priorização do PSF e de outras especialidades médicas; 4) o desconhecimento da homeopatia que leva a questionamentos sobre o tempo utilizado nas consultas, preconceitos e dificuldades na implantação daquilo que é novo; 5) a falta de estudos clínicos e econômicos que indiquem que a homeopatia deva ser incluída entre as prioridades de investimentos na saúde pública.

\section{Considerações finais}

As iniciativas de homeopatas para a implantação da homeopatia no SUS ficam na dependência de outras forças presentes no campo, como a demanda social, a simpatia e o conhecimento da racionalidade médica homeopática, bem como da PNPIC, por parte do gestor, para acolhê-los, apoiar e viabilizar medidas para implementar tal prática.

Os usuários que experimentaram esse tipo de atenção e que deixaram de recebê-la, pelas diferentes situaçóes relatadas nas entrevistas, mantiveram-se imobilizados, mesmo com a disponibilidade da participação e controle social por meio dos Conselhos Municipais de Saúde. Estes, no contexto desta pesquisa, mostraram-se não "empodeirados" de suas atribuiçóes, adquirindo posturas submissas aos gestores da saúde ${ }^{22,23}$.

Considera-se ainda que o Ministério da Saúde venha publicando, ano após ano, documentos (estratégias, pactos, programas e diretrizes) que apontam caminhos para efetivação do SUS, mas em nenhum deles existem citaçóes ou referência às Práticas Integrativas e Complementares e tampouco à Política que regulamenta essas práticas no SUS. As Práticas Integrativas e Complementares não estáo inseridas no Pacto pela Saúde, composto por três documentos - Pacto pela Vida, Pacto em Defesa do SUS e Pacto de Gestão ou nas Leis de Diretrizes Orçamentárias e Normas Operacionais Básicas -, tornando-se assim uma política isolada, pouco conhecida e de pouca influência ${ }^{24,25}$. O Pacto pela Saúde, documento importante, que vem sofrendo atualizaçóes conforme a realidade social, a prevalência das doenças e as principais causas de mortalidade, dispóe sobre as estratégias para o fortalecimento da atenção básica, dentre elas, o oferecimento de cursos de especialização para os profissionais, o que vem reforçar a possibilidade de ofertar a especializaçáo em homeopatia, uma vez que a importância das práticas integrativas e complementares para a atençấo básica de saúde, já vem sendo discutida nas Conferências de Saúde nos últimos 30 anos.

Concluiu-se, com base na análise dos dados recolhidos nesta pesquisa, que os fatores dificultadores da implementação da homeopatia no SUS estão associados principalmente à: desconhecimento da racionalidade homeopática; crenças de uma sociedade habituada à medicalização e ao "hospitalocentrismo"; falta de organização dos homeopatas em tornar conhecida a homeopatia e buscar instituiçóes públicas como campo de trabalho; a falta de estudos que demonstrem a efetividade e o custo/benefício da atenção em homeopatia; falta de percepção dos gestores em ter o homeopata como médico da família ou inserido nos Núcleos de Apoio à Saúde da Família ${ }^{26}$. Dessa forma, os facilitadores encontram-se atualmente subsumidos frente às dificuldades apontadas.

\section{Referências}

1. Luz MT. Racionalidades médicas e terapêuticas Alternativas. In: Camargo Junior KR. Racionalidades médicas: a medicina ocidental contemporânea. Rio de Janeiro: UERJ/Instituto de Medicina Social; 1993. p. 01-32. Série Estudos em Saúde Coletiva.

2. Ibáñez N, Marsiglia R. Medicina e Saúde: um enfoque histórico. In: Canesqui AM. Ciências Sociais e Saúde para o Ensino Médico. São Paulo: Hucitec; 2000. p. 49-74.

3. Barros NF. A construção de novos paradigmas na medicina: a medicina alternativa e a medicina complementar. In: Canesqui AM. Ciências Sociais e Saúde para o Ensino Médico. São Paulo: Hucitec; 2000. p. 201-216.

4. Queiroz MS. O sentido do conceito de medicina alternativa e movimento vitalista: uma perspectiva teórica introdutória. In: Nascimento MC. As duas faces da montanha estudos sobre medicina chinesa e acupuntura. São Paulo: Hucitec; 2006. p. 19-39.

5. Rodrigues DR, Anderson MIP. Saúde da Família: uma estratégia necessária. Rev Bras Med Fam Comunidade. 2011; 6(18): 21-24. 
6. World Health Organization - WHO. Estrategia de la OMS sobre medicina tradicional 2002-2005. Geneva; 2002.

7. Brasil. Ministério da Saúde. Secretaria de Atenção à Saúde. Departamento de Atenção Básica. Política Nacional de Práticas Integrativas e Complementares no SUS. Portaria n 971/GM/MS, de 3 de maio de 2006. Diário Oficial da República Federativa do Brasil, Brasília, DF, 4 maio 2006. [online] [acesso em 2009 Abr 05]. Disponível em: http://portal.saude.gov.br/portal/saude/profissional/ visualizar_texto.cfm?idtxt=28761\&janela=1

8. Barros NF. Política Nacional de Práticas Integrativas e Complementares no SUS: uma ação de inclusão. Cienc Saude Colet. 2006; 11(3):850.

9. Barros NF, Galhardi WMP. National Policy Integrative and Complementary Practices in the Brazilian Health System: steps towards the expansion of homeopathy. Homeopat J Facult Homeopat. London. 2008; 97(3):53.

10. Salles SAC. Homeopatia, Universidades e SUS: resistências e aproximações. São Paulo: Editora Hucitec; 2008. 210 p.

11. Brasil. Ministério da Saúde. O SUS e o Controle Social - guia de referência para Conselheiros Municipais. Brasília: Coordenação de Informações, Educação e Comunicação; 1998. [online] [acesso em 2010 Jul 10]. Disponível em: http://portalsaude.saude.gov.br/ portalsaude/index.cfm/?portal=pagina. visualizarArea\&codArea $=345$

12. Brasil. Ministério da Saúde. Participação Social na Gestão do SUS. Lei n 8142, 28 de dezembro de 1990. Dispõe sobre a participação da comunidade na gestão do Sistema Único de Saúde (SUS\} e sobre as transferências intergovernamentais de recursos financeiros na área da saúde e dá outras providências. Diário Oficial da República Federativa do Brasil, Brasília, DF, 31 dez. 1990. [online] [acesso em 2009 Set 05]. Disponível em: http://portal.saude.gov.br/portal/ arquivos/pdf/Lei8142.pdf

13. Tesser CD. Práticas complementares, racionalidades médicas e promoção da saúde: contribuições poucos exploradas. Cad Saúde Pública. 2009; 25(8):1732 -1742.

14. Barros NF, Tovems PAJ. Investigações qualitativas em práticas alternativas, complementares e integrativas. In Barros NF, Ceccatti JG, Turato ER. Pesquisa qualitativa saúde: múltiplos olhares. Campinas: Unicamp; 2005. p. 219-231.

15. Sampier RH, Collado CF, Lucio, PB. Metodologia de pesquisa. 3. ed. São Paulo: McGraw-Hill; 2006.
16. Bardin L. Análise de conteúdo. Traduzido por Luís A. Reto \& Augusto Pereira. 3. ed. Lisboa: Edições 70 Ltda.; 2004.

17. Minayo MCS. O Desafio do conhecimento: pesquisa qualitativa em Saúde. 8. ed. São Paulo: Hucitec; 2004. p. 9-28, p. 89-104, p. 197-247.

18. Instituto Brasileiro de Geografia e Estatística - IBGE. Brasil em Síntese. [online] [acesso em 2010 Abr 19]. Disponível em: http://www.ibge.gov. br/home/mapa_site/mapa_site.php\#populacao

19. Fundação Sistema Estadual de Análise de Dados. Perfil dos Municípios do Estado de São Paulo. [online] [acesso em 2008 Abr 02]. Disponível em: www.seade.gov.br/produtos/perfil/perfil.php

20. Estrela WL. Integralidade no Cuidado nas Medicinas Naturais: a resposta dos usuários ao medicamento homeopático. [Dissertação]. Rio de Janeiro: Universidade do Estado do Rio de Janeiro; 2006.

21. Salles SAC, Schraiber LB. Gestores do SUS: apoio e resistências à Homeopatia. Cad Saúde Pública. 2009; 25(1):195-202.

22. Gohn MG. Empoderamento e participação da comunidade em políticas sociais. Saúde Soc. 2004; 13(2):20-31.

23. Galhardi WMP, Barros NF. O ensino da homeopatia e a prática no Sistema Único de Saúde - SUS. Interface - Comunic., Saúde, Educ. 2008; 12(25):247-266.

24. Brasil. Ministério da Saúde. Secretaria Executiva. Departamento de Apoio à Descentralização. Coordenação-Geral de Apoio à Gestão Descentralizada. Diretrizes operacionais dos pactos pela Vida, em defesa do SUS e de gestão. 2. ed. Brasília; 2006. [online] [acesso em 2008 Fev 10]. Disponível em: http://portalsaude.saude.gov.br/ portalsaude/area/313/legislacao.html

25. Brasil. Ministério da Saúde. Pacto pela Saúde. Portaria n 399, de 22 de fevereiro de 2006. Divulga o Pacto pela Saúde 2006 - Consolidação do SUS e aprova as Diretrizes Operacionais do Referido Pacto. Diário Oficial da República Federativa do Brasil, Brasília, DF, fev. 2006. [online] [acesso em 2008 Fev 10]. Disponível em: http://portalsaude.saude. gov.br/portalsaude/area/313/legislacao.html

26. Brasil. Ministério do Estado da Saúde. Portaria GM no 154, de 24 de janeiro de 2008. Cria os Núcleos de Apoio à Saúde da Família - NASF. Diário Oficial da República Federativa do Brasil, Brasília, DF, jan. 2008. [online] [acesso em 2008 Fev 10]. Disponível em: http://portalsaude. saude.gov.br/portalsaude/area/313/legislacao.html 